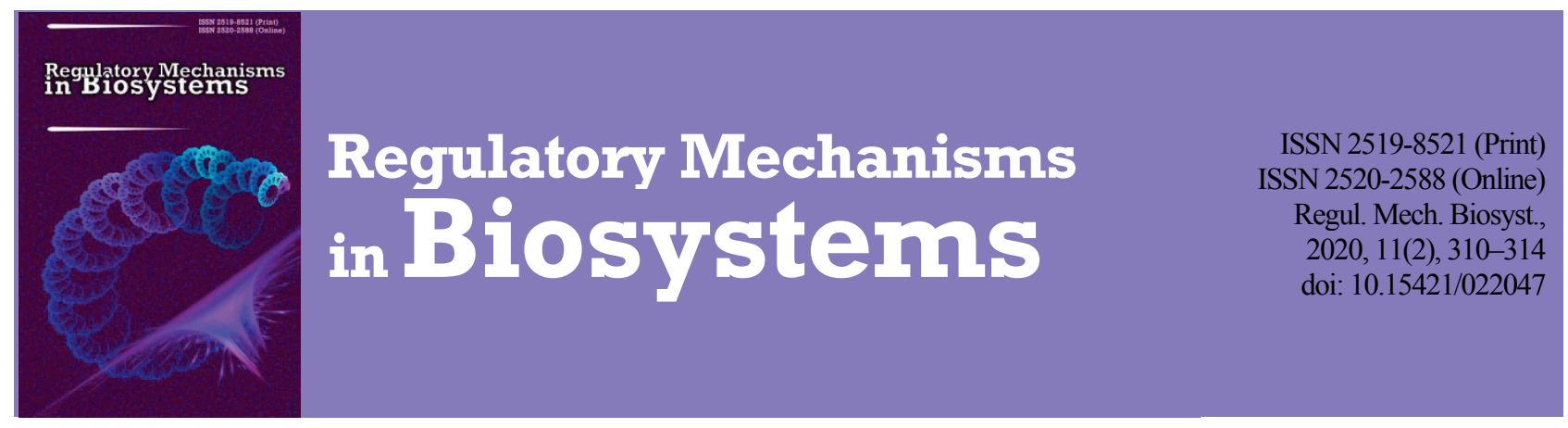

\title{
Modification of isolation methods and physico-biochemical properties of preparations of fungal oxidoreductases
}

\author{
O. V. Fedotov, Z. L. Usikova \\ Donetsk National Medical University, Kramatorsk, Ukraine
}

Article info

Received 17.04.2020

Received in revised form 12.05 .2020

Accepted 13.05.2020

Donetsk National

Medical University,

Machine-Builders

Boulevard, 39, Kramatorsk

84331, Ukraine.

Tel.: +38-068-717-87-87.

E-mail: bio.graff@ukr.net

\begin{abstract}
Fedotov, O. V., \& Usikova, Z. L. (2020). Modification of isolation methods and physico-biochemical properties of preparations of fungal oxidoreductases. Regulatory Mechanisms in Biosystems, 11(2), 310-314. doi:10.15421/022047
\end{abstract}

The results of the modification of methods for producing enzymatic preparations (EP) of peroxidases and catalases of extra- and intracellular finding from fungal cultures are presented. Strains of Flammulina velutipes F-vv, Lentinula edodes 523 and Pleurotus ostreatus P-01 were used as producers of oxidoreductases. The producers were cultured in glucose-peptone medium, modified for each strain. Protein fractionation was carried out by leaching with ammonium sulfate at a saturation of $40-70 \%$ for peroxidases and $80 \%$ for catalases. The obtained solutions of protein fractions were additionally subjected to purification by dialysis, gel filtration on Molselect G-50 and G-75 granules, and also freeze drying. The yield of enzymatic preparations per unit mass of mycelium and the volume of culture fluid were calculated. The individual characteristics of EP - enzymatic activity, the mass percentage of protein and associated amino acids, the ratio of the latter in groups depending on the nature of the radicals (amphotericity) of protein molecules are established. It was proved that the amino acid content in the proteins of fungal EP catalases and peroxidases indicates their acidic nature and this is confirmed by the $\mathrm{pH}$ values of aqueous solutions. Examination and toxicity testing of enzymatic preparations were carried out in certified laboratories, which confirmed their characteristics and compliance with safety requirements. The therapeutic properties of amino acids that are part of proteins or are in a free state in enzyme preparations are analyzed. In this way, the methods have been developed for producing enzymatic preparations of peroxidases and catalases of extra- and intracellular location, which allow new antioxidant enzymes with individual properties to be obtained, and, as a result, bring prospects for use in various industries and scientific research.

Keywords: Basidiomycetes; catalases; peroxidases; secretions; enzymatic preparations; characteristics.

\section{Introduction}

The use of enzymes and other physiologically active substances (PHAS) of a protein nature in various fields of production and therapy has a long tradition. However, there is especially intensive use of PHAS in the modern technological world, which explains the exacerbation of their shortage. Currently, the development of biotechnology, scientific discoveries in enzymology have made enzyme preparations an indispensable participant in many technologies. The use of enzymes can increase the speed of technological processes in various industries, significantly increase the output of finished products, improve their quality, save valuable raw materials and reduce the amount of waste. Enzyme preparations are also widely used in medicine. Enzymes in medical practice are used as diagnostic (enzymodiagnostics) and therapeutic (enzymotherapy) agents. In addition, enzymes are widely used as specific reagents to identify a number of substances. In response to this shortfall, the volume and nomenclature of PHAS products is increasing annually in the world. However, the work to find new producers, create new drugs of prolonged action, purify enzyme preparations, improve their stability, etc. is relevant and is underway at an accelerated pace (Fedotov \& Voloshko, 2014; Singh et al., 2016; Vitak et al., 2017).

To obtain enzyme preparations (EP) for food use, organs and tissues of farm animals, cultivated plants, special strains of microorganisms (microscopic fungi, bacteria) are used. Plant enzymes are specific to their natural substrate, which determines the high efficiency of their action on plant raw materials. In the microbial world, one can find a specific producer of a particular enzyme and their selection is almost unlimited, since these enzymes are involved in the total circulation of organic matter. This explains the widespread use of microbial enzymes in artificial technologies. From animal raw materials a limited range of enzyme preparations are received, which, being more expensive, are used less often than microbials (Hameed et al., 2018).

Large-scale research on fungi of different systematic groups has revealed among them promising producers of various biologically active substances (Wasser, 2011; Chien et al., 2016). In particular, basidium mushrooms attract the attention of scientists in many fields. This is due to significant successes in the study of their metabolism processes, the creation of collections of pure crops, progress in the technical equipping of cultivation processes and, as a result, the possibility of widespread practical use (Fedotov \& Usikova, 2020).

For example, oxidoreductase of basidiomycetes, in particular peroxidases and catalases, are of scientific and commercial interest in industrial uses. These enzymes have been widely used, namely peroxidase, which is used as a diagnostic reagent or marker enzyme in enzyme-linked immunosorbent assay, as a preservative in the food industry; catalase as a component of sorbent for stabilization of blood products, for cold sterilization of milk, cheese, eggs, in processes of organic synthesis, polymerization of rubber, etc. (Mhamdi et al., 2010; Lushchak, 2016).

Screening research has shown the ability of basidiomycetes to synthesize enzymes of all known classes and allowed the most productive strains in this respect to be selected (Elisashvili et al., 2018). Basidium enzyme preparations isolated from culture fluid or mycelium have several advantages: they are cheaper than animals; do not contain specific toxic impurities that form molds and bacteria, and the methods for their preparation are more economically viable than for enzymes of plant origin (Mittler, 2002). In addition, new enzymes may have distinctive characteristics - 
molecular weight and amino acid sequence, optimum temperature and $\mathrm{pH}$ of action, substrate specificity, etc.

It is worth examining all these aspects that have been covered extensively in recent decades in original articles and in review papers (Gurung et al., 2013; Fedotov, 2017; Nandi et al., 2019).

Catalase (hydrogen peroxidase: hydrogen peroxide oxidoreductase EC 1.11.1.6) is an enzyme found in the cells of virtually all aerobic organisms. Along with the decomposition of hydrogen peroxide and thereby protecting the cell from its toxic effects, by participating in the prooxidantantioxidant system, the enzyme catalyzes a number of metabolically significant reactions. Therefore, catalase is one of the most intensively studied enzymes.

However, a number of important issues related to the catalytic mechanism, the metabolic role of catalysis, and the feasibility of applications remain largely unclear and require further experimental research. It should also be noted that in addition to isoenzymes due to species specificity, multiple forms of catalase have been established for different taxonomic groups of living organisms within the same species. However, the nature and mechanism of isoenzyme formation in many cases remain unclear, despite intensive research.

Biotechnology involves the study of the possibility of induction and regulation of the biosynthesis of the final product, in this case - catalase. In most cases, the concentration of catalases has been found to be regulated according to the metabolic requirements of the cell. The catalase level is usually associated with oxygen metabolism. The enzyme is absent under anaerobic conditions and induced by oxygen. So oxygen is an important regulator of catalysis synthesis that acts indirectly. In this aspect, it is also assumed that there is a connection between the synthesis of the components of the respiratory chain and the catalase.

Physicochemical properties of typical catalase were investigated. It is established that the catalytic activity of catalase does not depend on the $\mathrm{pH}$ change in the range of 5.0-10.5 (in catalase microscopic fungi Penicillium vitale and Aspergillus niger - in the range of $\mathrm{pH} 2.0-7.0$ ). Typical catalases are resistant to organic solvents, most of them heat-stable. Thus, incubation of Aspergillus niger catalase at $70{ }^{\circ} \mathrm{C}$ for $60 \mathrm{~min}$ does not lead to a decrease in activity, and in the case of bacterial catalase Rhodospirillum rubrum and Micrococcus luteus incubation for $5 \mathrm{~min}$ at $50^{\circ} \mathrm{C}$ revealed activation of 1.5-2.0 times. The experiments show the inactivation of catalase by hydrogen peroxide, which depends on the concentration of the peroxide and not the enzyme (Hassan et al., 2017; Nandi et al., 2019).

Continued work on the search for producers and the study of properties is explained by the widespread practical use of catalase. In particular, in the food industry, glucose oxidase is used in combination with catalase as an antioxidant and for sugar in the storage of products; stabilization of wines, non-alcoholic beverages, juices, fatty and meat-dairy products and more. The use of catalase in the cold sterilization of milk, cheese, eggs improves the quality of products, preserving their properties. For example, Aspergillus niger is used in the food industry to remove hydrogen peroxide residues, a sterilizing agent in the production of food concentrates, sterile milk, melange and other products. Catalase preparations can also be useful in a number of chemical industry processes related to the use of hydrogen peroxide: bleaching of materials, organic synthesis, polymerization of rubber, production of porous materials. There is a practical use of catalase in medicine for diagnostic purposes and as a component of the sorbent for the stabilization of blood products. The most relevant and painful is the use of catalase alone or in combination with other enzymes (superoxide dismutase) in the treatment of specific diseases that require the efficient removal of oxygen radicals (Mittler, 2002; Hassan et al., 2017).

As already mentioned, the complex primary antioxidant protection of cells and the body as a whole is carried out by the enzymes superoxide dismutase, catalase and peroxidase. The second enzyme in our review is peroxidase (EC 1.11.1.7), aheme loosely glycoprotein. The catalytic properties of it are strictly specific to hydrogen peroxide, but this enzyme is widespread activity to other, quite diverse in the structure of substrates. Some researchers believe that peroxidases have one active center, which includes a trivalent iron atom, which does not change its valence. However, the multifunctionality of peroxidase does not exclude the possible presence of a second catalytic site on the surface of the protein molecule. Functionality and role of peroxidases are widely studied. In particular, enzymes belonging to the class of oxidoreductases, namely peroxidases, play a leading role in the oxidative degradation of lignin. Accordingly, the most widespread practical application in the process of lignin oxidation has been found for fungal peroxidases: LiP, MnP, laccase. As for horseradish peroxidase, its use is limited by a small amount of research into the oxidation of simple monomeric phenolic structures. In general, the results of studying the characteristics of enzymes of the family of peroxidases of fungal and plant origin show their similar structure, but it is emphasized that higher stability and $\mathrm{pH}$-optimum are characteristic for plant peroxidases (Hameed et al., 2018; Elisashvili et al., 2018; Metri et al., 2018).

Interest in the study and use of peroxidase continues unabated. Horseradish peroxidase (HRP) is the most widely used enzyme in in enzyme immunoassay kits with spectrophotometric detection. Chemiluminescent analysis using HRP has been implemented, which is extremely popular, as well as fluorescence analysis using the Ampex Red kit. Currently, highly sensitive biosensors are being developed on the basis of recombinant peroxidases for the determination of various compounds in complex multicomponent mixtures, including in the analysis of environmental pollution.

In recent years, peroxidase preparations from new sources have appeared on the market. These include: the fungal peroxidase Coprinus cinereus (Arthromyces ramosus), produced commercially in native and recombinant forms; peroxidase from the waste of soybean production and peroxidase from the super-productive culture of batat cells.

It should be noted that the most promising enzyme for practical use is a recombinant variant of the fungal peroxidase (Coprinus cinereus), which has high stability under extreme conditions. Extremely high thermostability is different from recently obtained palm peroxidases. Work in this direction is continuing (Hameed et al., 2018).

Based on the above, the aim and objectives of the research is the modification of methods for producing enzyme preparations of peroxidases and catalase extracellular and intracellular origin from cultures of basidiomycetes and study of their composition and physico-biochemical properties.

\section{Material and methods}

Highly productive strains of basidiomycetes Flammulina velutipes Fvv, Lentinula edodes 523 and Pleurotus ostreatus P-01 - catalase and peroxidase producers (Fedotov \& Voloshko, 2011, 2014). The cultures are deposited in the Collection of the Cap Fungi Cultures of the M. G. Kholodny Institute of Botany of the National Academy of Sciences of Ukraine (IBK) (Bisko et al., 2016; Fedotov \& Usikova, 2020). The strains were cultured superficially at $27 \pm 1^{\circ} \mathrm{C}$ on modifications of the glucose-peptone medium $\left(\mathrm{g} / \mathrm{dm}^{3}\right)$ : glucose -10.0 ; peptone $-3.0 ; \mathrm{KH}_{2} \mathrm{PO}_{4}-0.6 ; \mathrm{K}_{2} \mathrm{HPO}_{4}-$ $0.4 ; \mathrm{MgSO}_{4} \times 7 \mathrm{H}_{2} \mathrm{O}-0.5 ; \mathrm{CaCl}_{2}-0.05 ; \mathrm{ZnSO}_{4} \times 7 \mathrm{H}_{2} \mathrm{O}-0.001 ;$ distilled water - up to $1 \mathrm{dm}^{3}$. Reagents were purchased from Sigma (Germany) (Fedotov \& Bisko, 2018). Inoculum - 10-day mycelial cultures of selected strains on wort-agar accounted for $5-7 \%$ of the volume of glucose-peptone medium. The strains were cultured for 12-15 days, until the culture reached maximum enzymatic activity.

Modification of the methods of selection of EP was carried out by experimentally determining the ratio of the amount of inoculum introduced into the volume of the nutrient medium, aseptic and cultivation time of the producers, analytical trituration of $\left(\mathrm{NH}_{4}\right)_{2} \mathrm{SO}_{4}$ concentration of the desired enzyme, the time and conditions of dialysis.

The activity of the oxidoreductases from the mycelium and the culture fluid (CF) was determined by spectrophotometric methods: peroxidase activity (POX activity) - by the intensity of the coloration of the oxidation product o-dianisidine $\mathrm{H}_{2} \mathrm{O}_{2}$ and expressed in conventional units the amount of enzyme that catalyzes the oxidation of $1 \mu \mathrm{mol}$ o-dianisidine in 1 minute; CAT activity - by staining the reaction product $\mathrm{H}_{2} \mathrm{O}_{2}$ with ammonium molybdate and expressed in mkat corresponding to the amount of enzyme involved in the conversion of 1 micromole of hydrogen peroxide per second under the specified conditions (Voloshko, 2011).

The protein concentration in the mycelium and CF was determined by the Lowry-Folin method (Voloshko, 2014). Based on the obtained results, the specific peroxidase and catalase activity (ASPA), which is equal to the ratio of activity of the corresponding enzyme (A) and protein concentration (CP). The evaluation of the fermentation process was carried out on the following indicators: biomass concentration $(\mathrm{X})$ and its 
conversion to absolutely dry biomass, biomass productivity $(\mathrm{Qx})$, product performance (Qp), substrate yield (Yp/s) (Fedotov \& Bisko, 2018).

The experiments were carried out in triplicate. Data are expressed as mean values \pm error. Statistical analysis was performed using OriginPro 8.5.1 software (Origin-Lab Corportion, USA), and samples were compared using one-way ANOVA (indicators of the fermentation process and enzyme activity).

\section{Results}

Protein precipitation by fractions from an aqueous mycelium homogenate (M) extract was carried out by adding ammonium sulfate in the range of $60-80 \%$. The yield of EP catalase activity was $0.18 \pm 0.02 \mathrm{~g}$ with
$1 \mathrm{~kg}$ of mycelium (product performance $-\mathrm{Qp}=6.25 \times 10^{-4} \mathrm{~g} / \mathrm{dm}^{3} \times \mathrm{h}$; substrate yield $-\mathrm{Yp} / \mathrm{s}=1.5 \times 10^{-2} \mathrm{~g} / \mathrm{g}$ ) and $0.15 \pm 0.02 \mathrm{~g}$ with $1 \mathrm{dm}^{3}$ culture fluid $\left(\mathrm{Qp}=5.21 \times 10^{-4} \mathrm{~g} / \mathrm{dm}^{3} \times \mathrm{h} ; \mathrm{Yp} / \mathrm{s}=1.3 \times 10^{-2} \mathrm{~g} / \mathrm{g}\right)$. The catalase activity $(\mathrm{E})$ of the enzyme preparations obtained is not inferior to the activity of industrial preparations and is: strain F. velutipes $\mathrm{F}-\mathrm{vv}-\mathrm{EM}=1320.5$ $\pm 1.5 \mathrm{mkat} / \mathrm{mg}, \mathrm{ECF}=4077.9 \pm 2.3 \mathrm{mkat} / \mathrm{mg}$; strain $P$. ostreatus P-01 $\mathrm{EM}=1500.3 \pm 1.6 \mathrm{mkat} / \mathrm{mg}, \mathrm{ECF}=9593.5 \pm 5.5 \mathrm{mkat} / \mathrm{mg}$.

The mass percentage of bound amino acids and protein in the EP of catalase activity is individual (Table 1), amino acids are located depending on the nature of the radicals - amphoteric.

The protein content of EP of mycelial catalase exceeds $55 \%$. This is most likely due to the accuracy of fractionation and the degree of purification: the presence of high-polymer polysaccharides and other compounds.

\section{Table 1}

Aminoacid composition of enzymatic preparations of oxidoreductases strains of basidium fungi

\begin{tabular}{|c|c|c|c|c|c|c|c|c|}
\hline \multirow{4}{*}{ Aminoacid } & \multicolumn{2}{|c|}{ Enzymatic preparations catalase } & \multicolumn{6}{|c|}{ Enzymatic preparations peroxidase } \\
\hline & $\begin{array}{l}\text { Flammulina } \\
\text { velutipes } \mathrm{F}-\mathrm{vv}\end{array}$ & $\begin{array}{c}\text { Pleurotus } \\
\text { ostreatus } \mathrm{P}-01\end{array}$ & \multicolumn{2}{|c|}{$\begin{array}{l}\text { Lentinula } \\
\text { edodes } 523\end{array}$} & \multicolumn{2}{|c|}{$\begin{array}{c}\text { Flammulina } \\
\text { velutipes } \mathrm{F}-\mathrm{vv}\end{array}$} & \multicolumn{2}{|c|}{$\begin{array}{c}\text { Pleurotus } \\
\text { ostreatus } \mathrm{P}-01 \\
\end{array}$} \\
\hline & \multicolumn{8}{|c|}{ Aminoacidcontent, $\mathrm{mg} / 100 \mathrm{mg}$} \\
\hline & mycelium & mycelium & $\mathrm{CF}$ & mycelium & $\mathrm{CF}$ & mycelium & $\mathrm{CF}$ & mycelium \\
\hline \multicolumn{9}{|c|}{ Non-polaraminoacids } \\
\hline Alanine & 4.52 & 3.65 & 6.88 & 6.74 & 2.32 & 2.15 & 3.21 & 2.67 \\
\hline Glycine & 3.84 & 3.85 & 7.79 & 5.01 & 4.80 & 7.01 & 3.93 & 2.79 \\
\hline Hydroxyproline & 6.20 & 5.04 & ND & ND & ND & ND & ND & ND \\
\hline Isoleucine* & 5.79 & 5.30 & 3.58 & 5.53 & 5.56 & 6.25 & 3.66 & 3.41 \\
\hline Leucine* & 5.36 & 6.71 & 8.74 & 8.91 & 8.87 & 8.91 & 9.32 & 8.51 \\
\hline Proline & 7.32 & 5.01 & 8.34 & 2.12 & 2.93 & 4.60 & 3.31 & 3.94 \\
\hline Valine* & 5.95 & 5.21 & 5.63 & 7.20 & 5.34 & 4.06 & 3.78 & 3.93 \\
\hline \multicolumn{9}{|c|}{ Polaraminoacids } \\
\hline Cyst(e)ine & 6.02 & 4.93 & 3.43 & 0.35 & 1.37 & 1.45 & 1.07 & 0.29 \\
\hline Methionine* & 3.93 & 2.46 & 0.09 & 1.24 & 5.57 & 2.07 & 1.62 & 1.87 \\
\hline Serine & 5.67 & 4.53 & 7.64 & 4.76 & 3.53 & 3.00 & 4.09 & 3.28 \\
\hline Threonine * & 0.96 & 0.54 & 6.85 & 5.20 & 3.00 & 3.99 & 3.44 & 3.65 \\
\hline \multicolumn{9}{|c|}{ Aromaticaminoacid } \\
\hline Phenylalanine * & 1.71 & 1.60 & 6.47 & 5.08 & 10.03 & 4.93 & 9.20 & 9.73 \\
\hline Tyrosine & 14.33 & 17.68 & 5.58 & 4.10 & 9.72 & 7.84 & 8.76 & 9.09 \\
\hline \multicolumn{9}{|c|}{ Negatively charged aminoacids } \\
\hline Aspartic acid & 12.18 & 19.19 & 12.52 & 11.07 & 12.70 & 14.08 & 15.56 & 15.38 \\
\hline Glutamic acid & 5.34 & 5.34 & 8.78 & 15.74 & 10.76 & 12.39 & 13.11 & 12.40 \\
\hline \multicolumn{9}{|c|}{ Positively charged aminoacids } \\
\hline Arginine* & 3.69 & 3.40 & 1.37 & 7.62 & 4.04 & 5.74 & 4.78 & 5.98 \\
\hline Histidine & ND & ND & 1.96 & 0.28 & 2.60 & 2.95 & 3.04 & 3.35 \\
\hline Lysine* & 7.19 & 5.56 & 4.35 & 9.05 & 6.86 & 8.58 & 8.12 & 9.73 \\
\hline $\begin{array}{c}\text { \% protein in enzymatic } \\
\text { preparations }\end{array}$ & 55.83 & 57.07 & 20.05 & 39.72 & 39.63 & 50.49 & 37.81 & 42.41 \\
\hline
\end{tabular}

Note: * are essential amino acids, ND-not determined.

The glycine content of polar, hydrophilic amino acids in EP is most likely influenced by the introduction of a peptone enzyme in the nutrient medium having up to $2.22 \%$ of this amino acid content of nitrogen. The investigated EP proteins could be attributed to acidic only by the number of negatively charged aspartic and glutamic amino acids. But this assumption is true when in proteins they are not in the form of glutamine and asparagine, which is not possible to prove with acid hydrolysis. An indirect indication of the advantage in the structure of EP proteins of acidic amino acids may be that the $0.1 \%$ aqueous solution of the enzyme strain F-vv had $6.2 \pm 0.1 \mathrm{pH}$; strain P-01 $-5.3 \pm 0.1 \mathrm{pH}$. The content in the enzyme proteins of the basic, positively charged amino acids of arginine and histidine is much lower than the previous ones and cannot significantly affect the nature of the protein.Each of these classes of amino acids is characterized by the specialized metabolic pathways, their metabolism is of great physiological importance. Thus, thanks to the processes of exchange of three amino acids with polar (hydrophilic) uncharged R-groups - glycine, glutamine and cysteine - an extremely important biologically active substance, glutathione, is formed. It is an extremely important component of antioxidant protection and has many relevant functions.

Thus, the first obtained fungal $\mathrm{EP}$ catalase strain $F$. velutipes $\mathrm{F}-\mathrm{vv}$ and strain $P$. ostreatus $\mathrm{P}-01$ have individual characteristics. The mass percentage of protein and amino acid content in the proteins of fungal EP catalases has been established, which indicates their acidic nature and is confirmed by the $\mathrm{pH}$ values of aqueous solutions. Expertise and toxicity testing of catalase enzyme preparations were carried out in certified la- boratories, which confirmed their characteristics and compliance with safety requirements. At the second stage, attention was paid to peroxidase activity. Protein precipitation by fractions from aqueous mycelium homogenate extract and $\mathrm{CF}$ was carried out at $5 \pm 1{ }^{\circ} \mathrm{C}$ by adding ammonium sulfate to $40-70 \%$ and $40-60 \%$ saturation, respectively. The obtained solutions of protein fractions were subjected to freeze-drying and determined peroxidase activity enzyme preparations that have the form of powder from light gray to light cream color, well soluble in water.

The yield of enzyme preparations was $0.16 \pm 0.02 \mathrm{~g} / \mathrm{kg}$ of mycelium and $0.15 \pm 0.02$ per $1 \mathrm{dm}^{3}$ of the culture filtrate.

Peroxidase activity $(\mathrm{E})$ of enzyme preparations is equal to: strain L. edodes $523-\mathrm{E}_{\mathrm{CF}}=4.47 \pm 0.10 \mathrm{E} / \mathrm{mg}, \mathrm{E}_{\mathrm{M}}=4.47 \pm 0.09 \mathrm{E} / \mathrm{mg}$; strain F. velutipes $\mathrm{F}-\mathrm{vv}-\mathrm{E}_{\mathrm{CF}}=4.77 \pm 0.10 \mathrm{E} / \mathrm{mg}, \mathrm{E}_{\mathrm{M}}=9.10 \pm 0.20 \mathrm{E} / \mathrm{mg}$; strain P. ostreatus $\mathrm{P}-01-\mathrm{E}_{\mathrm{CF}}=3.43 \pm 0.09 \mathrm{E} / \mathrm{mg}, \mathrm{E}_{\mathrm{M}}=3.23 \pm 0.07 \mathrm{E} / \mathrm{mg}$.

The mass percentage of bound amino acids and protein in the enzyme preparations of fungal peroxidases was determined using an amino acid analyzer model AAA-881, after acid hydrolysis of enzymatic preparations. Amino acid composition and data on the mass percentage of protein content in the enzyme preparations peroxidase obtained are given in Table 1, where the amino acids are located depending on the nature of the radicals (amphoteric) of the protein molecules. The data are presented without error, since they represent the exact results of amino acid analysis on one sample of the enzymatic preparations of exo- and endoperoxidases (EPCF and EPM) of the tested strains of $L$. edodes 523, F. velutipes F-vv and P. ostreatus P-01. Obtained data on the content of amino acids and protein 
indicate their individual character of the investigated proteins and preparations. As already noted, the mushroom enzyme preparations of milkclotting enzymes of exogenous nature had a protein content of 17.4 (strain Fibuloporia mollusca A-020) to $43.6 \%$ (strain Amyloporia lenis A-004). Protein content in EP of mycelial catalase of strain $F$. velutipes $\mathrm{F}-\mathrm{vv}$ and strain $P$. ostreatus $\mathrm{P}-01$ is slightly higher than $55 \%$ - higher than the mentioned milk-clotting enzymes (Fedotov \& Velygodska, 2016). Protein content in EPCF peroxidase of the studied strains is in the range 20.0639.63; and in EPM - 39.72-50.49. The highest protein content in the EP was recorded for the F-vv strain of $F$. velutipes, the lowest for the strain L. edodes 523. Enzyme preparations obtained from the culture filtrate contain a smaller proportion of protein and essential amino acids compared to EP mycelium peroxidase. Protein content in EP of the mentioned milkclotting enzymes and peroxidases is most likely due to their origin and the presence of high-polymer polysaccharides in them.

Speaking about the amino acid composition of the investigated proteins, oxyproline from the group of nonpolar, hydrophobic amino acids, which, unlike the results of the analysis of EP of milk-clotting action, was not detected in the protein composition of peroxidase strains of $L$. edodes 523, F. velutipes $\mathrm{F}-\mathrm{vv}$ and $P$. ostreatus $\mathrm{P}-01$. The glycine content of polar, hydrophilic amino acids in EP is most likely influenced by the introduction into the nutrient medium of enzymatic peptone, which has up to $2.2 \%$ of this amino acid from nitrogen content. The investigated proteins of EP could be attributed to acidic only by the number of negatively charged aspartic and glutamic amino acids. But this assumption is true when in proteins they are not in the form of glutamine and asparagine, which is not possible to prove with acid hydrolysis. An indirect indication of the advantage in the structure of EP proteins of acidic amino acids may be that $0.1 \%$ aqueous solutions of enzyme preparations showed a low $\mathrm{pH}$, which was equal to: $\mathrm{EP}_{\mathrm{CF}}-4.85 \pm 0.09$ and $\mathrm{EP}_{\mathrm{M}}-5.10 \pm 0.07$ strain L. edodes 523; $\mathrm{EP}_{\mathrm{CF}}-5.75 \pm 0.11$ and $\mathrm{EP}_{\mathrm{M}}-5.80 \pm 0.10$ strain $F$. velutipes $\mathrm{F}-\mathrm{vv}$; $\mathrm{EP}_{\mathrm{CF}}-$ $5.38 \pm 0.08$ and $\mathrm{EP}_{\mathrm{M}}-5.80 \pm 0.09$ strain $P$. ostreatus $\mathrm{P}-01$. The content in the enzyme proteins of the basic, positively charged amino acids arginine and histidine is much lower than the previous ones and cannot significantly affect the nature of the protein.

Thus, for the first time enzyme preparations of fungal peroxidase exoand endogenous origin of strain $L$. edodes 523 , strain $F$. velutipes $\mathrm{F}-\mathrm{vv}$ and strain $P$. ostreatus $\mathrm{P}-01$ were obtained. EP peroxidases have individual characteristics of protein content, and proteins have bound amino acids. A mass percentage of amino acid content of EP proteins of fungal peroxidases was established, which indicates the acidic nature of the proteins and is confirmed by the $\mathrm{pH}$ values of their aqueous solutions. Expertise and toxicity studies of EP peroxidases were conducted in the certified laboratories, which confirmed their characteristics and compliance with the requirements for safety parameters.

\section{Discussions}

The results of studies, summarized in numerous publications (Yoshizawa, 2004, 2012; Uneyama \& Takeuchi, 2012; Chien et al., 2016; Singh et al., 2016), indicate a gradual (with the accumulation of new data) increased attention and interest in antioxidant oxidoreductases as enzymes, which catalyze one of the key reactions in cellular oxygen metabolism, decomposition and peroxide metabolism, as well as a quantity of redox reactions important for metabolism involving hydrogen peroxide and other substrates. Data is collected on certain characteristics and properties of these enzymes, including their composition. Here it is worth paying attention to certain therapeutic properties of amino acids that are part of the proteins of enzyme preparations or are in a free state.

The hydrophilicity of amino acids largely depends on their polarity, which is associated with the charge of their side groups. Five aliphatic amino acids (alanine, valine, glycine, isoleucine and leucine) contain weakly polar side groups. Sulfur amino acids (methionine and cysteine), as well as one of the aromatic amino acids, phenylalanine, have a weak polarity. On the basis of their hydrophobicity, these amino acids are poorly soluble in water. The remaining amino acids contain positively charged polar side groups, and therefore they are more hydrophilic and dissolve well in water. The polarity of amino acids has a significant effect on the structure of the protein, its properties and functions. It should be empha- sized that most hydrophobic amino acids are indispensable (valine, isoleucine, leucine, methionine and phenylalanine). Two other essential amino acids (threonine and tryptophan) are characterized by moderate hydrophilicity (Yoshizawa, 2012).

So, in the group of non-polar amino acids the following was recorded. Glycine in the protein is more common than other amino acids. It is a precursor in the biosynthesis of porphyrin and purine bases. Glycine, like gamma-aminobutyric acid, is a inhibitory mediator. Nowadays, indications for the use of glycine are stressful conditions, psychoemotional stress, increased irritability, emotional lability, neurosis, vascular vegetative dystonia, the effects of traumatic brain injury, encephalopathy, and sleep disturbances. Glycine is also used as a means of improving mental capacity and reducing psycho-emotional stress during remission in cases of encephalopathy, organic lesions of the central and peripheral nervous system. Amino acid analysis of fungal EP showed that they all contain this amino acid in moderation, most of it $-7.79 \mathrm{mg} / 100 \mathrm{mg}$ in EP peroxidases from the culture fluid of the strain L. edodes 523 and $7.01 \mathrm{mg} / 100 \mathrm{mg}$ from the mycelium of the strain $F$. velutipes F-vv. Essential amino acids, leucinetogether with isoleucine and valine make up about $20 \%$ in the structure of muscle proteins. Of fungal EP their highest content reaches $9.32 \mathrm{mg} / 100 \mathrm{mg}$ in the EP of peroxidase from the mycelium of the strain $P$. ostreatus P-01; $6.25 \mathrm{mg} / 100 \mathrm{mg}$ in the EP of peroxidases from the mycelium of the $F$. velutipes strain F-vv; $7.20 \mathrm{mg} / 100 \mathrm{mg}$ in EP peroxidase from the mycelium of the strain $L$. edodes 523 . Valine is one of the starting materials for the biosynthesis of pantothenic acid (vitamin $\mathrm{B}_{5}$ ) and penicillin. Research in rats has shown that valine increases muscle coordination and reduces the body's sensitivity to pain, cold and heat. In our case, the high content of this amino acid is $7.20 \mathrm{mg} / 100 \mathrm{mg}$ observed in the EP peroxidase mycelium of the strain $L$. edodes 523 . Alanine is part of many proteins and a number of biologically active compounds. It is easily converted into glucose in the liver. This process is called the glucose-alanine cycle and is one of the main pathways of gluconeogenesis in the liver (Uneyama \& Takeuchi, 2012). By structure, proline is the only coded amino acid in which the amino group is a heterocycle fragment. It refers to stress amino acids, and its amount can be used to benchmark the cells or organisms (Yoshizawa, 2012). The highest content of this amino acid $-8.34 \mathrm{mg} / 100 \mathrm{mg}$ is installed in the EP peroxidases from the culture fluid of the strain L. edodes 523.

Polar amino acids such as cysteine, threonine, serine and their content in the EP have been discussed above. Particular attention should be paid to the sulfur-containing polar amino acid cysteine. It can be present in the protein in two forms: either in the form of cysteine, or in the form of a dipeptide - cystine, which is a complex of two cysteine molecules covalently linked to each other via a disulfide bridge. On the basis of this property, cysteine has an important function in stabilizing the structure of a protein molecule. Cysteine plays a key role in the formation of insulin and immunoglobulins (antibodies). In these proteins, due to disulfide cysteine bridges, different polypeptide chains are connected into one protein molecule. Such cross-links are usually absent in intracellular proteins, but are widely represented in secretory proteins. Methionine has been shown to improve memory and interrupt neural degeneration. There is also evidence that a deficiency of methionine, acetylcysteine, glutamine contributes to the development of human immunodeficiency. Methionine is used to treat and prevent diseases and toxic liver damage, with atherosclerosis, can have a moderate antidepressant effect (probably due to the effect on the synthesis of adrenaline) (Yoshizawa, 2012). In this research, the highest content of methionine $5.57 \mathrm{mg} / 100 \mathrm{mg}$ was recorded in the EP peroxidases of the culture fluid of the strain $F$. velutipes $\mathrm{F}-\mathrm{vv}$.

Aromatic amino acid phenylalanine and tyrosine is known to serve as a biosynthetic precursor of catecholamines - dioxyphenylalanine, dopamine, adrenaline, norepinephrine, melanin, thyroxine, tyramine, protein-peptide hormones, in particular thyroid hormones and thyroxine. Clinical researches have shown that tyrosine-containing supplements help control depression and anxiety that are not treatable by other medicine (Uneyama \& Takeuchi, 2012). The highest tyrosine content $-17.68 \mathrm{mg} / 100 \mathrm{mg}$ found in the EP catalase from the mycelium of the strain P. ostreatus P-01.

Negatively charged amino acids glutamic acid and aspartic acid are neurotransmitter excitatory amino acids (Yoshizawa, 2004). As already mentioned, these amino acids in the investigated proteins contain the 
highest amount: the highest content of glutamic acid - $15.74 \mathrm{mg} / 100 \mathrm{mg}$ in EP peroxidases from the mycelium $L$. edodes 523; aspartic acid $19.19 \mathrm{mg} / 100 \mathrm{mg}$ in EP catalase from mycelium P. ostreatus P-01.

Positively charged amino acids. It is proved that lysine is necessary for the growth and restoration of tissues, the formation of antibodies, hormones, enzymes, albumin, as well as to maintain nitrogen balance in the cell and the body. It absorbs and stores calcium, maintains healthy blood vessels, and exhibits hypocholesterolemic activity. Lysine has a pronounced antiviral effect, in particular for colds. It has antioxidant, angio-, cardio- and nephroprotective properties (Chien et al., 2016). According to the data obtained, all EPs contain this amino acid. The highest lysine content, in the range of $9.05-9.73 \mathrm{mg} / 100 \mathrm{mg}$, is characteristic of peroxidase preparations of the mycelium strains $P$. ostreatus $\mathrm{P}-01$ and $L$. edodes 523, respectively. It was established that histidine is a component of the active sites of many enzymes, is a precursor to histamine biosynthesis, promotes tissue growth and repair, and is mainly found in hemoglobin. Used in the treatment of rheumatoid arthritis, allergies, ulcers and anemia. Histidine deficiency can cause hearing loss (Uneyama \& Takeuchi, 2012). The results of our study show the highest content of this amino acid $3.35 \mathrm{mg} / 100 \mathrm{mg}$ in EP peroxidases from the mycelium of the strain P. ostreatus $\mathrm{P}-01$.

In addition, it is worth noting the results of the analysis of the amino acid composition of catalase of the strain of the fungus Penicillium vitale (Singh et al., 2016). It shows a high content of aspartic and glutamic acids, glycerol, alanine, leucine and phenylalanine. In the protein part of the catalase there is a low content of tyrosine, tryptophan, histidine and proline. The relatively low content of the last two amino acids indirectly indicates a high degree of spiralization of the polypeptide chain and the compactness of the catalase molecule. This can be seen from the results of the analysis, and is especially clear for catalase of microbial origin.

In this connection, the study of the amino acid composition of proteins, including enzymes, has both theoretical and practical significance. The latter is aimed at solving applied problems. In particular, our analysis of the problem indicates the significant promise of the direction in creating the technology for the production of protein concentrates, prophylactic drugs and protein compositions based on mushroom cultures.

\section{Conclusions}

Thereby, on the basis of improving the composition of the nutrient medium and the preparation method, fungal enzymatic preparations of catalase of intracellular finding strains of Pleurotus ostreatus and Flammulina velutipes and enzyme preparations of peroxidases of intra- and extracellular finding strains of Pleurotus ostreatus, Flammulina velutipes and Lentinula edodes were firstly isolated. According to a study of enzymatic preparations physicochemical properties have individual characteristics. Hence, their enzymatic activity, the mass percentage of protein and amino acids in fungal EP catalases and peroxidases were established, which indicates their acidic nature and is confirmed by the $\mathrm{pH}$ values of aqueous solutions. Examination and toxicity testing of enzymatic preparations were carried out in certified laboratories, which confirmed their characteristics and compliance with safety requirements. Generally, the results of preliminary screening of highly active producers of oxidoreductases among representatives of Basidiomycetes, the study of the features of their cultivation and biosynthesis, became the basis for the modification of the methods for culturing producers and obtaining enzymatic preparations of peroxidases and catalases of various origins. All this in the future will allow us to continue research in this direction to obtain new antioxidant enzymes that have broad prospects for use in scientific research and various industries.

We express our sincere gratitude to the research associates of the Mycology Department the M. G. Kholodny of Institute of Botany, National Academy of Sciences of Ukraine for cooperation, provided materials of the Collection of Cap Mushroom Cultures (IBK), which has the status of the National Heritage of Ukraine.

\section{References}

Bisko, N. A., Lomberg, M. L., Mytropolska, N. Y., \& Mykchaylova, O. B. (2016). The IBK mushroom culture collection. Kyiv, M. G. Kholodny Institute of Botany, National Academy of Sciences of the Ukraine. Alterpres, Kyiv.

Chien, R. C., Lin, L. M., Chang, Y. H., Lin, Y. C., Wu, P. H., Asatiani, M. D., Wasser, S. G., Krakhmalnyi, M., Agbarya, A., Wasser, S. P., \& Mau, J. L. (2016) Anti-inflammation properties of fruiting bodies and submerged cultured mycelia of culinary-medicinal higher Basidiomycetes mushrooms. International Journal of Medicinal Mushrooms, 18(11), 999-1009.

Classic Enzyme: Horseradish Peroxidase (2018). Journal of Chemical, Environmental and Biological Engineering, 2(2), 52-59.

Elisashvili, V., Kachlishvili, E., \& Asatiani, M. D. (2018). Efficient production of lignin-modifying enzymes and phenolics removal in submerged fermentation of olive mill by-products by white-rot Basidiomycetes. International Biodeterioration and Biodegradation, 134, 39-47.

Fedotov, O. V. (2017). Condition of the prooxidant-antioxidant system of some strains of Basidiomycetes. Regulatory Mechanisms in Biosystems, 8(1), 77-83.

Fedotov, O. V., \& Bisko, N. A. (2018). Effect of phenolic substances and hydrogen peroxide on antioxidant activity of some strains of Basidiomycetes. Innovative Biosystems and Bioengineering, 2(1), 4-10.

Fedotov, O. V., \& Usikova, Z. L. (2020). The study of vegetative incompatibility strains of Basidiomycetes. Innovative scientific researches: European development trends and regional aspect. Baltija Publishing, Riga. Pp. 136-155.

Fedotov, O. V., \& Velygodska, A. K. (2016). Milk-clotting and antioxidant activity of enzyme preparations of fungi strains of the order Polyporales s.l. The scientific heritage. Biological Sciences, 2(2), 71-76.

Fedotov, O. V., \& Voloshko, T. E. (2014). Otrymannya ta analiz fermentnykh preparativ oksydoreduktaz deyakykh bazydiomitsetiv [Production and analysis of enzyme preparations of oxidoreductases of some Basidiomycetes]. Microbiology and Biotechnology, 3, 65-76 (in Ukrainian).

Gurung, N., Ray, S., Bose, S., \& Rai, V. (2013). A broader view: Microbial enzymes and their relevance in industries, medicine and beyond. BioMed Research International, 2013, 1-18.

Hameed, A., Divine, M. S., Mazhar, K., Sm Faysal, B., \& Sm Saker, B. (2018). Structure, function and applications of a classic enzyme: Horseradish peroxidase. Journal of Chemical, Environmental and Biological Engineering, 2(2), 52-59.

Hassan, W., Noreen, H., Rehman, S., Gul, S., Kamal, M. A., Kamdem, J. P., Zaman, B., \& da Rocha, J. B. T. (2017). Oxidative stress and antioxidant potential of one hundred medicinal plants. Current Topics in Medicinal Chemistry, 17(12), 1336-1370.

Lushchak, V. I. (2016). Time-course and intensity-based classifications of oxidative stresses and their potential application in biomedical, comparative and environmental research. Redox Report, 21(6), 262-270.

Metri, Y., Warly, L., Metri, Y., Fachry, A. R., \& Astuti, P. (2018). The enzymic degradation of lignin by white-rot fungi. Pakistan Journal of Nutrition, 17, 71-75.

Mhamdi, A., Queval, G., Chaouch, S., Vanderauwera, S., Van Breusegem, F., \& Noctor, G. (2010). Catalase function in plants: A focus on Arabidopsis mutants as stress-mimic models. Journal of Experimental Botany, 61(15), 4197-4220.

Mittler, R. (2002). Oxidative stress, antioxidants and stress tolerance. Trends Plant Science, 7, 405-410.

Nandi, A., Yan, L. J., Jana, C. K., \& Das, N. (2019). Role of catalase in oxidative stress- and age-associated degenerative diseases. Oxidative Medicine and Cellular Longevity, 2019, 9613090.

Singh, R., Kumar, M., Mittal, A., \& Mehta, P. K. (2016). Microbial enzymes: Industrial progress in 21st century. Biotechnology, 6, 1-15.

Uneyama, H., \& Takeuchi, K. (2012) New therapeutic strategy for amino acid medicine: Preface. Journal of Pharmacological Sciences, 118(2), 129-130.

Vitak, T. Y., Wasser, S. P., Nevo, E., \& Sybima, N. O. (2017). Enzymatic system of antioxidant protection of erythrocytes in diabetic rats treated with medicinal mushrooms Agaricus brasiliensis and Ganoderma lucidum (Agaricomycetes). International Journal of Medicinal Mushrooms, 19, 697-708.

Voloshko, T. E., \& Fedotov, O. V. (2011). Skryninh shtamiv bazydiomitsetiv za aktyvnistyu antyoksydantnykh oksydoreduktaz [Screening of basidiomycetes strains on the antioxidant activity of oxidoreductases]. Microbiology and Biotechnology, 16, 69-81 (in Ukrainian).

Wasser, S. P. (2011). Current findings, future trends, and unsolved problems in studies of medicinal mushrooms. Applied Microbiology and Biotechnology, $89,1323-1332$.

Wasser, S. P. (2017). Medicinal mushrooms in human clinical studies. Part I. Anticancer, oncoimmunological, and immunomodulatory activities: A review. International Journal of Medicinal Mushrooms, 19(4), 279-317.

Yoshizawa, F. (2004). Regulation of protein synthesis by branched-chain amino acids in vivo. Biochemical and Biophysical Research Communications, 313, 417-422.

Yoshizawa, F. (2012). New therapeutic strategy for amino acid medicine: Notable functions of branched chain amino acids as biological regulators. Journal of Pharmacological Sciences, 118(2), 149-155. 